\title{
Alteamento e conservação de vogais médias postônicas não finais em dois estilos de fala
}

\author{
Rising and conservation of non final posttonic mid vowels in two speech styles
}

Alessandra De Paula ${ }^{1}$

Doutora em Língua Portuguesa pela Universidade Federal do Rio de Janeiro, atua como Professora Adjunta de Língua Portuguesa e Filologia do Departamento de Letras da Faculdade de Formação de Professores da Universidade do Estado do Rio de Janeiro (UERJ/FFP). No âmbito do Projeto Português do Brasil e Português de Sáo recentemente publicou com a Professora Doutor Silvia Figueiredo Brandão, coordenadora do referido Projeto, o artigo Vogais em contexto postônico náo final em variedades do português: questöes teóricas (DE PAULA; BRANDAO, 2015), o qual apresenta os resultados primordiais da pesquisa sociolinguística que aqui será complementada.
RESUMO: A pesquisa sociolinguística variacionista realizada por De Paula (2015) no Estado do Rio de Janeiro investigou o processo de mudança que ocorre no vocalismo postônico não final do português. Os resultados demonstram que o processo de alteamento atinge ambas as vogais médias postônicas não finais /e/ e /o/, que estão em plena variação com as vogais altas /i/e /u/ neste contexto (abób[o]ra abób[u]ra; pêss[e]gu pêss[i]gu). Isto indica que a mudança para o sistema simétrico de três vogais /i a u/ já está prevista no nível subjacente da fala fluminense. Tais resultados diferem do sistema assimétrico /i E a U/, defendido por Câmara Jr (1970). Além disso, a complementação dos resultados com um questionário e um teste de leitura foi fundamental para encontrar e analisar muitas palavras proparoxítonas que não apareceram nos corpora sociolinguísticos Tal etapa da pesquisa demonstrou que o alteamento, que é praticamente categórico na fala espontânea de pessoas que estudaram até o Ensino Fundamental, é inibido gradualmente com o aumento da escolaridade e do monitoramento do discurso, o que leva os falantes a recuperarem as variantes conservadoras [e] e, até mesmo, [o].

PalaVras-chaVE: Sociolinguística; Fonologia; Alteamento; Vocalismo; Postônico.

ABSTRACT: The variationist sociolinguistics research done by De Paula (2015) in Rio de Janeiro State studied the process of change that occurs in the non-final posttonic vocalism in Portuguese. The results show that the raising process affects the both non-final posttonic mid vowels /e/ and /o/, which are in full variation with the high vowels /i/ and /u/ in this context (abób[o]ra abób[u]ra; pêss[e]gu pêss[i]gu). It indicates that the change to the three vowels symmetrical system /i a u/ is already foreseen in underlying level of the speech in Rio de Janeiro State. These results differ from the asymmetric system /i E a U/, defended by Câmara Jr (1970). Moreover, the complementation of the results with a questionnaire and a reading test was fundamental to find and analyze many proparoxytone words that did not appear in the sociolinguistic corpora This step of research showed that the raising process, which is virtually categorical in spontaneous speech of people who reached up to primary education, is gradually inhibited depending on the level of education and speech monitoring, which does speakers recover the conservative variants [e] and even [o].

KEYwoRDS: Sociolinguistics; Phonology; Raising; Vocalism; Posttonic. 


\section{Introdução}

O vocalismo postônico medial do português do Brasil - referente à penúltima sílaba das proparoxítonas - tem sido alvo de discussão teórica no que diz respeito às oposições fonológicas entre as vogais médias e altas nessa posição, especialmente por serem pouco numerosas as palavras da língua que apresentam esse contexto e não existirem pares mínimos distintivos que ajudem a determinar os limites entre os fonemas /e, i/ e /o, u/.

Embora ainda sejam poucos os autores que se dedicaram ao tema, alguns estudos foram realizados (entre eles, VIEIRA, 1994, 2002, 2009; MAGALHÃES, 2011; RAMOS, 2009; RIBEIRO, 2007), especialmente com o objetivo de investigar o processo de alteamento que atinge as vogais médias /e/ e /o/. Esses trabalhos têm sido realizados a partir da interpretação de Câmara Jr (1970) que defende existir assimetria no processo de alteamento que atinge as vogais médias nessa posição. Segundo ele, o quadro vocálico tônico sofre redução total da série posterior em /U/ (ép/U/ca), mas a série anterior mantém dois segmentos /E i/, permanecendo assim a oposição entre as vogais médias anteriores e a vogal alta, em um quadro de quatro segmentos: /i E a U/. Câmara Jr afirma que, na cidade do Rio de Janeiro, uma realização como *núm[i]ro seria rechaçada pelos falantes (1970, p. 43-44).

Bisol $(2003 ; 2010)$ expande a discussão ao considerar que um sistema assimétrico de vogais não é estável nas línguas naturais e que o português do Brasil tende a estabilizar esse contexto fonológico em três vogais /i a u/, concluindo a mudança para a vogal alta também na articulação anterior. Para ela, o que Câmara Jr interpretou como um quadro de quatro vogais na verdade é uma flutuação entre o quadro de cinco vogais /i E a O u/ e o quadro de três /I a U/, propostos por este mesmo autor para as posições pretônica e postônica final, respectivamente.
Os trabalhos variacionistas de De Paula $(2010,2015)$ e De Paula e Brandão (2012a; 2012b; 2015 e outros) no Estado do Rio de Janeiro objetivaram verificar a proposta de Câmara Jr em dados das falas culta e popular, rural e urbana do Estado, no período desde os anos 1970 até os anos 2000. A principal hipótese levantada foi a de que ambas as vogais altas /i/ e /u/ sejam variantes produtivas na fala fluminense. Além disso, considerou-se que os índices de alteamento aumentariam com o passar do tempo em todos segmentos da comunidade de fala fluminense. As autoras esperavam ainda encontrar indicativos de que esse processo de mudança esteja em fase final de implementação, de acordo com a proposta de Weinreich; Labov e Herzog (1978).

Os resultados de De Paula e Brandão têm demonstrado que uma das principais características do vocalismo postônico medial diz respeito à diferença entre o comportamento da vogal anterior /e/ e da posterior /o/ nessa posição: o alteamento tem sido refreado apenas no contexto da anterior /e/. Por outro lado, os falantes estudados não apenas demonstraram aceitar realizações da vogal alta [i], em palavras como número, como também produziram tais vogais com frequência relevante na fala espontânea. Assim, embora a interpretação de Câmara Jr tenha algum respaldo na variação encontrada na fala fluminense, a frequente realização da vogal média anterior como alta /i/ nesse contexto fonológico parece confirmar a proposta de Bisol.

No contexto da discussão apresentada, o presente trabalho propõe-se a expor os resultados de uma das etapas da pesquisa empreendida por De Paula (2015) com base em questionários e teste de leitura aplicados a falantes cariocas. Tal etapa buscou investigar o alteamento dessas vogais em diferentes estilos de fala, em consonância com a teoria laboviana (LABOV, 1972), como complementação à análise variacionista previamente realizada.

Convém destacar duas motivações para a aplicação dos questionários e do teste de leitura. Primeiramente, o conjunto de dados com vogais 
médias postônicas mediais é extremamente pequeno, principalmente se comparado com os outros quadros vocálicos (para mais informações, cf. ARAÚJO et al., 2007; DE PAULA, 2010, 2014), tanto em variedade de lexemas como em frequência de ocorrência. Muitos itens lexicais proparoxítonos conhecidamente em uso no português não ocorreram nas entrevistas sociolinguísticas levantadas e os que foram encontrados geralmente figuraram na fala de poucos informantes, sendo então raros os vocábulos e contextos fonéticos que puderam ser vislumbrados em todas as células sociais controladas, fato que limitou a análise variacionista realizada.

Outra razão provém dos resultados da observação de sete cartas de Atlas linguísticos do Estado do Rio de Janeiro (LIMA, 2006; ALMEIDA, 2008) em De Paula $(2009,2010)$, os quais já haviam apontado que o monitoramento do discurso em situação de questionário pode refrear o processo de alteamento, sendo favorável à realização mais conservadora das vogais, com abertura média.

Assim, a aplicação dos questionários e do teste de leitura serviu não apenas para estudar um número maior de itens lexicais proparoxítonos com vogais /e/ e /o/ postônicas mediais, que não poderiam ter sido averiguadas sem essa complementação metodológica, como para equilibrar o número e a variedade de dados encontrados entre todos os informantes gravados. Destaca-se, por outro lado, que a análise de dados levantados através de questionários é limitada com relação a entrevistas do tipo DID (diálogo entre informante e documentador), no aspecto de que a análise multivariada é inviabilizada, restando apenas a observação de índices percentuais.

Resta explicitar, por fim, a configuração do conjunto de dados analisados no que diz respeito aos estilos de fala nele representados. Nas entrevistas, há menor preocupação por parte do falante com a elocução e nelas esperou-se encontrar resultados mais próximos da fala cotidiana. Já no levantamento através de questionários o indivíduo está mais atento ao seu discurso, pois o modelo de perguntas e respostas imprime um caráter mais formal à situação de fala. Além disso, o inquérito conta com trechos de leitura, que, pela especificidade semântica das proparoxítonas procuradas, muitas vezes foram elaborados com uma linguagem formal ou até mesmo técnica. Portanto, nesse tipo de levantamento, foi possível vislumbrar a realização das vogais estudadas em uma situação discursiva em que o falante está mais atento a sua fala, de forma que o confronto entre os corpora permitiu comparar o comportamento linguístico de indivíduos com perfis sociais semelhantes produzindo estilos diferentes: a fala espontânea e a fala monitorada, nos termos de Labov (1972).

\section{Corpora sociolinguísticos - fala espontânea}

A tese de doutorado de De Paula (2015) reúne os últimos resultados da sua pesquisa que investigou o fenômeno do alteamento na posição postônica não final, averiguando porque o processo de alteamento já está implementado no que se refere à vogal posterior, mas ainda encontra resistência no âmbito da vogal anterior, averiguando a natureza dessa resistência. Para isso, a autora verificou as propostas de Câmara Jr e de Bisol, já comentadas.

A pesquisa variacionista realizada nas falas culta e popular do Estado do Rio de Janeiro comparou amostras de 1970 e 1980 e da primeira década de 2000, a partir de um conjunto de dados recolhidos em 166 entrevistas do tipo DID. Os dados das décadas de 1970/80 advêm de: 78 entrevistas do corpus APERJ (Atlas Etnolinguístico dos Pescadores do Estado do Rio de Janeiro), composto apenas por homens do Norte e do Noroeste do Estado que estudaram, no máximo, até a $4^{a}$ série do Ensino Fundamental; 25 entrevistas do corpus PEUL 80 (Programa de Estudos sobre o Uso da Língua), referentes a homens e mulheres cariocas com, no máximo, Ensino Médio completo; e 18 entrevistas do corpus de fala culta NURC- RJ (Norma Urbana Oral Culta do 
Rio de Janeiro), composto por homens e mulheres da capital Rio de Janeiro que concluíram o Ensino Superior. Para o estudo da década de 2000, foram consideradas: 35 entrevistas do Projeto Concordância RJ, que inclui homens e mulheres dos diferentes níveis de escolaridade; e 10 entrevistas do corpus PEUL 2000, que, à semelhança da amostra de 1980, apresenta indivíduos escolarizados até o Ensino Médio, no máximo.

Os corpora apresentaram um total de 1.844 ocorrências de proparoxítonas com vogal média postônica não final e foram analisadas no programa Goldvarb-X. O universo lexical das entrevistas está composto por 89 diferentes vocábulos, $43 \mathrm{com} / \mathrm{e} /$ e $46 \mathrm{com}$ /o/ postônicos não finais, os quais estão listados a seguir.

- Vogal /e/: alfândega, almôndega, amássemos, Aristóteles, câmeras, centímetro, célebre, cérebro, córrego, estudássemos, exógenos, fenômeno, fôlego, gênero, hidrômetro, hipótese, ímpeto, indígena, intérprete, inúmeros, Mariângela, milímetro, nádega, número, ópera, pálpebra, paralelepípedo, parâmetro, perímetro, pêssego, prótese, quilômetro, quiséssemos, tivéssemos, tráfego, úlcera, uníssemos, útero, velocípede, vértebras, véspera, víscera, vivêssemos.

- Vogal /o/: abóbora, Acrópole, Adrianópolis, agrícola, âncora, árvore, autônomo, biólogas, bússola, carnívoro, catálogo, catástrofe, cômoda, cômodo, cômoro, Débora, diálogo, época, Florianópolis, fósforo, gastrônomo, Heliópolis, herbívoro, ídolo, incômodo, índole, Mariópolis, mármore, método, metrópole, monótono, Nápoles, Nilópolis, pároco, Pentágono, pérola, Petrópolis, polígono, psicólogo, sambódromo, semáforo, símbolo, sociólogo, Távola, Teresópolis, tômbolos.

As proparoxítonas com vogal /e/ totalizaram 485 ocorrências e as com vogal /o/, 1359. Os resultados para o vocalismo postônico não final aqui discutidos devem ser, então, relativizados, considerando-se que a ocorrência da vogal anterior /e/ restringe-se a $26,3 \%$ dos dados.
Como foi relatado na introdução deste trabalho, esse universo lexical é muito pequeno se comparado com os outros quadros vocálicos do português, tanto em variedade de lexemas como em frequência de ocorrência. Além disso, ele condiciona fortemente os resultados correspondentes às variáveis linguísticas controladas no trabalho, como o contexto fonético em que as vogais aparecem, por exemplo. Isso significa que a seleção de uma variável linguística como relevante pelo programa de análise estatística, por exemplo, a consoante em contexto subsequente, está geralmente relacionada a ocorrência de apenas alguns itens lexicais, como a presença das consoantes $/ \mathrm{m} / \mathrm{e} / \mathrm{t} /$ no radical -metro: milímetro, centímetro, quilômetro etc. Como consequência, todas as variáveis linguísticas acabaram sendo desconsideradas e, em contrapartida, De Paula $(2010,2015)$ realizou uma minuciosa análise lexical dos corpora.

\section{Resultados gerais da análise sociolinguística}

Esta seção apresenta os resultados gerais para os dados de fala espontânea fluminense. A análise multivariada realizada será aqui apresentada de maneira sucinta com o intuito de ser comparada com os resultados dos questionários e do teste de leitura, focos deste artigo, e pode ser observada com detalhe na tese de De Paula (2015) ou nos artigos dela derivados (DE PAULA; BRANDÃO, 2015, 2012b e outros).

A análise estatística dos corpora NURC, PEUL, APERJ e Concordância confirmou que, na fala fluminense, as vogais médias /e/ e /o/ estão em variação com as altas /i/ e / $\mathrm{u} /$, nas duas sincronias. Como explicitam os percentuais gerais a seguir (Tabelas 1 e 2), referentes aos corpora da região metropolitana do Estado, a vogal posterior é realizada alta na maioria absoluta dos dados sociolinguísticos de fala popular e culta, quando não é apagada, nas duas épocas estudadas: 
Tabela 1 - Índices gerais da variação de vogais médias postônicas mediais na fala fluminense - Décadas de 1970/80

\begin{tabular}{|c|c|c|c|c|}
\hline \multicolumn{5}{|c|}{ Corpora NURC e PEUL 80} \\
\hline & Alteamento & Manutenção & Apagamento & Total \\
\hline \multirow{2}{*}{ Vogal /e/ } & 58 & 68 & 02 & 128 \\
\hline & $45,3 \%$ & $53,1 \%$ & $1,6 \%$ & $100 \%$ \\
\hline Exemplo & ['vefpire] & ['vehtebirf] & ['vefpre] & \\
\hline \multirow{2}{*}{ Vogal /o/ } & 243 & 11 & 57 & 311 \\
\hline & $78,1 \%$ & $3,6 \%$ & $18,3 \%$ & $100 \%$ \\
\hline Exemplo & [aw'tõ numu] & [a'boboie] & [aw'tõme [] & \\
\hline
\end{tabular}

Tabela 2 - Índices gerais da variação de vogais médias postônicas mediais na fala fluminense - Década de 2000

\begin{tabular}{|c|c|c|c|c|}
\hline \multicolumn{5}{|c|}{ Corpora Concordância RJ e PEUL 2000} \\
\hline & Alteamento & Manutenção & Apagamento & Total \\
\hline \multirow{2}{*}{ Vogal /e/ } & 40 & 34 & 05 & 79 \\
\hline & $50,6 \%$ & $43,1 \%$ & $6,3 \%$ & $100 \%$ \\
\hline Exemplos & [fe'nõminu] & [fe'nõmenu] & ['nũf] & \\
\hline \multirow{2}{*}{ Vogal /o/ } & 327 & 06 & 18 & 351 \\
\hline & $93,2 \%$ & $1,7 \%$ & $5,1 \%$ & $100 \%$ \\
\hline Exemplos & ['zpuke] & ['ع:poke::] & ['вpв] & \\
\hline
\end{tabular}

Por outro lado, de acordo com a análise dos dados de /e/ - a única vogal que apresenta variação passível de análise estatística -, concluiu-se que a resistência da vogal média no contexto anterior, já acusada de certa forma por Câmara Jr, existe apenas no nível fonético, especialmente na fala dos indivíduos mais escolarizados (ou que monitoram o seu discurso, segundo outras etapas da pesquisa já comentadas). Câmara Jr sugeriu que o alteamento para [i] era inadmissível pelos cariocas, enquanto os dados demonstram a usualidade desse processo, levando à variação entre [e] e [i] na realização do elemento fonológico que anteriormente era /e/.

A fala escolarizada foi fator preponderante para a manutenção de /e/ em cada uma das décadas estudadas, conforme exposto na referida tese. A Tabela 3, a seguir, apresenta o resultado final da análise da vogal /e/ no contraste entre os dados de fala culta e popular das duas sincronias estudadas ${ }^{1}$ :

Tabela 3 - Fator condicionador do alteamento da vogal média anterior postônica medial na fala da Região Metropolitana do Rio de Janeiro - Décadas de 1970/80 e 2000

\begin{tabular}{llccc}
\hline Variáveis & Fatores & Oco & \% & Peso Relativo \\
& Fundamental & $\mathbf{3 5 / 3 7}$ & $\mathbf{9 4 , 6}$ & $\mathbf{0 . 9 3 8}$ \\
Escolaridade & Médio & $23 / 34$ & 67,6 & 0.645 \\
& Superior & $40 / 129$ & 31,0 & 0.281 \\
\hline
\end{tabular}

Sig.: 0.000; Input: 0.535 .

Os pesos relativos deixam claro que o aumento gradual da escolaridade desfavorece o alteamento, sendo fator preponderante para a restrição do processo. Além disso, a observação dos falantes com até o Ensino Fundamental, em todas as etapas de análise, demonstrou que a mudança já está prevista no nível subjacente da fala popular, com um quadro simétrico /i a u/, e há quase categoricidade na realização das vogais como altas, à semelhança do contexto postônico final. As Tabelas 4 e 5, a seguir, apresentam, separadamente, os resultados de cada sincronia estudada e nelas é possível ver que a escolaridade foi variável selecionada em ambas as análises:

${ }^{1}$ Foi excluído desta análise final o corpus APERJ, que não tem equivalente geográfico na década de 2000. 
Tabela 4 - Fatores condicionadores do alteamento da vogal média anterior postônica medial na fala fluminense - Décadas de 1970/80

\begin{tabular}{llccc}
\hline \multicolumn{5}{c}{ Corpora APERJ e NURC } \\
Variável & Fatores & Oco & $\%$ & Peso Relativo \\
\multirow{2}{*}{ Escolaridade } & Ensino Superior & $19 / 87$ & 21,8 & 0.052 \\
& De 0 a 4 anos & $\mathbf{2 2 9 / 2 4 5}$ & $\mathbf{9 3 , 5}$ & $\mathbf{0 . 7 3 7}$ \\
\hline
\end{tabular}

Sig.: 0.000; Input: 0.836 .

Tabela 5 - Fatores condicionadores do alteamento da vogal média anterior postônica medial na fala fluminense - Década de $2000^{2}$

\begin{tabular}{llccc}
\hline Variáveis & Fatores & Oco & \% & Peso Relativo \\
Sexo & Homem & $\mathbf{2 9 / 4 1}$ & $\mathbf{7 0 , 7}$ & $\mathbf{0 . 7 1 9}$ \\
& Mulher & $11 / 33$ & 33,3 & 0.237 \\
\multirow{2}{*}{ Escolaridade } & Médio e Superior & $28 / 60$ & 46,7 & 0.376 \\
& Até Fundamental II & $\mathbf{1 2 / 1 4}$ & $\mathbf{8 5 , 7}$ & $\mathbf{0 . 8 9 7}$ \\
\hline
\end{tabular}

Sig.: 0.000; Input: 0.560 .

Os percentuais de alteamento de /e/ entre os falantes que estudaram até o Ensino Fundamental II são de 93,5\% (P.R. 0.737) e 85,7\% (P.R. 0.897) nas décadas de 1970/80 e 2000, respectivamente, dados que demonstram a produtividade do alteamento e o estágio muito avançado da mudança no sentido do quadro simétrico de três vogais. Fica assim demonstrado que, no Rio de Janeiro, a assimetria é resultado da resistência de /e/ entre os falantes mais escolarizados.

\footnotetext{
2 A variável sexo dos informantes de 1970/80 não foi analisada no Goldvarb por ausência de mulheres no corpus APERJ, que é constituído por pescadores do interior do RJ, mas foi discutida no âmbito do NURC em De Paula (2010; 2015). Lembra-se ainda que não há falantes com Ensino Médio nos corpora de $1970 / 80$.
}

\section{Questionários e teste de leitura - fala monitorada}

Como explicado, os dados discutidos nessa seção complementam as entrevistas do tipo DID, concisamente apresentadas acima, e foram obtidos através de um questionário, composto por perguntas e identificação de figuras, e de um teste de leitura de textos.

Conforme planejado, com essa nova amostra foi possível comparar os resultados obtidos nas entrevistas com um número maior de itens lexicais proparoxítonos, de frequência de uso mais ou menos alta na fala espontânea, de acordo com a análise de frequência de uso e a classificação lexical desenvolvidas em De Paula (2010). Assim, foi possível não só ampliar o universo lexical da investigação, como observar os mesmos vocábulos sendo realizados por falantes de diferentes perfis sociais, com maior regularidade do que as entrevistas permitem. Por fim, o contraste entre os dados das entrevistas e do questionário/leitura permitiu observar a mudança de comportamento dos falantes em situações diversas de comunicação, mais ou menos formais.

Deve-se lembrar, mais uma vez, que esses dados não são estilisticamente semelhantes aos demais por conta da diferenciação da técnica de recolha, que aqui é mais formal e, inclusive, se vale de uma etapa de leitura, ainda mais artificial que o questionário. Por outro lado, esta foi uma estratégia que permitiu registrar realizações de várias palavras, que são utilizadas esporadicamente pelos falantes brasileiros, mas que raramente figuram nos corpora estudados. Além disso, foi possível comparar a realização das proparoxítonas em contextos de uso diversos e, assim, ter mais material que ajude a refletir sobre a relação entre o fenômeno estudado, o conjunto das palavras proparoxítonas e a formalidade do discurso.

Para o controle dos informantes, foram seguidos os critérios metodológicos da Sociolinguística. O teste foi aplicado a 18 informantes 
cariocas, distribuídos por três faixas etárias (18 a 35 anos; de 36 a 55 anos e 56 anos ou mais), três níveis de escolaridade (até $2^{\circ}$ segmento do Ensino Fundamental, Ensino Médio e Ensino Superior) e sexo (masculino e feminino).

Os inquéritos tiveram duração média de 30 minutos. Como já foi dito, ele é composto de três etapas e cada uma apresenta características distintas: (i) um questionário de perguntas e respostas, (ii) a identificação de figuras e (iii) a leitura de textos. Considera-se que os dados da etapa (i) são os mais espontâneos, vista a interação semiespontânea entre o informante e o documentador. Já as respostas de (ii) são mais objetivas e, nelas, o falante altera o seu estilo de fala com relação à etapa (i), estando mais atento à palavra selecionada para as respostas. A leitura, naturalmente, é a estratégia mais formal de recolha de dados e seu estilo se destaca das outras duas, mas permitiu angariar também proparoxítonas pouco usuais ou técnicas, difíceis de serem obtidas através de perguntas ou figuras.

A lista abaixo contém os 71 itens proparoxítonos levantados com o questionário e a leitura, $41 \mathrm{com}$ vogal /e/ e $30 \mathrm{com}$ vogal /o/ postônicas não finais:

- Vogal/e/: adúltero, alienígena, almôndega, áspero, bafômetro, bípede, câmera, cárcere, célebre, centímetro, cérebro, cócegas, fenômeno, fôlego, frutífero, gênero, hipótese, hóspede, ímpeto, indígena, íntegro, mamífero, milímetro, número, ópera, pálpebra, parâmetro, parêntese, pêssego, próspero, prótese, quilômetro, síntese, sonífero, taxímetro, tráfego, termômetro, úlcera, útero, velocípede, véspera.

- Vogal/o/: abóbora, agrícola, ancora, apóstolo, autódromo, autônomo, benévolo, biólogo, brócolis, carnívoro, catástrofe, cômodo, diálogo, fósforo, frívolo, horóscopo, ídolo, índole, mármore, método, monótono, pérola, pólvora, própolis, psicólogo, sambódromo, semáforo, símbolo, ufólogo, víbora.
Como foi dito, a escolha desses termos buscou abarcar proparoxítonas sabidamente usuais na fala coloquial, mas que nem sempre foram encontradas nas entrevistas ou encontradas em quantidade expressiva. Assim, foi possível equilibrar o número de ocorrências de cada termo no conjunto de cada vogal, /e/ e /o/. Selecionaram-se mais proparoxítonas com a vogal /e/, por ser aquela que apresenta mais variação na sua realização e o alvo principal das discussões fonológicas dentro do fenômeno investigado. Foram levantadas de formas diversas - perguntas, figuras e leituras -, sendo que os vocábulos biólogo, $c a-$ tástrofe, gênero, síntese e véspera foram alvo de perguntas e também de leitura.

As perguntas focalizaram os itens áspero, bafômetro, fenômeno, fôlego, gênero, hóspede, mamífero, número, ópera, quilômetro, síntese, sonífero, taxímetro, úlcera, útero, véspera (17 itens), com /e/; e abóbora, agrícola, âncora, apóstolo, autônomo, biólogo, carnívoro, catástrofe, cômodo, diálogo, ídolo, monótono, pólvora, própolis e psicólogo (15 itens), com /o/.

Os vocábulos conseguidos com o uso de figuras foram almôndega, câmera, centímetro, cérebro, cócegas, fôlego, milímetro, pálpebra, parêntese, pêssego, termômetro, tráfego, velocípede (13 itens), com /e/; e autódromo, brócolis, fósforo, horóscopo, mármore, pérola, sambódromo, semáforo e símbolo (09 itens), com /o/.

Como dito, a etapa de leitura permitiu levantar algumas proparoxítonas que dificilmente seriam conseguidas através de perguntas ou, principalmente, figuras por serem termos pouco usuais, que têm sinônimos mais frequentes na fala coloquial e representarem, muitos deles, ideias abstratas. São as palavras: adúltero, alienígena, bípede, cárcere, célebre, gênero, hipótese, ímpeto, indígena, íntegro, parâmetros, próspero, prótese, síntese, véspera (15 itens), com /e/; e benévolo, biólogo, catástrofe, frívolo, índole, método, ufólogo e víbora (08 itens), com /o/.

Para não expor o tema que foi foco desta pesquisa e obter o máximo de naturalidade do informante ao produzir as vogais investigadas, aten- 
tou-se para diversos procedimentos no decorrer das gravações. O principal deles foi o investigador alegar o interesse em conhecer as palavras usadas naturalmente do dia-a-dia dos cariocas. Para tanto, incluíram-se, entre as 32 perguntas que focalizam as proparoxítonas, 16 distratores com outros padrões acentuais. Além de alternar com o padrão acentual predominante no inquérito, os distratores também focalizaram a variação lexical regional e, assim, foram aproveitados para tirar a atenção de algumas perguntas menos naturais, ou até muito simples, elaboradas para conseguir os itens desejados. Dessa forma, perguntas como, por exemplo, Qual é o órgão em que o bebê cresce na barriga da mãe? (útero) e $A, B, C$ são letras. 1, 2, 3 são o quê? (números) foram alternadas com perguntas do tipo Como você chama uma pessoa que não gosta de trabalhar? e Além do feijão preto, como chama aqui no Rio um feijão que é marrom?

Sobre essa etapa da pesquisa, considerou-se a já citada hipótese baseada nos resultados encontrados por De Paula (2010) na observação de dados de /e/ e /o/ postônicos não finais registrados em sete cartas dos Atlas linguísticos AFeBG e MicroAFERJ, que também foram elaborados através de questionários. Seus resultados apontaram um contraste na produção dessas vogais por falantes com pouca escolaridade na fala da Região Metropolitana do Rio de Janeiro: os falantes não cultos preservaram muito mais as vogais médias neste formato de levantamento, menos natural, em que permanecem muito mais atentos ao seu discurso. Assim, esperou-se que, em comparação com os resultados das entrevistas, fossem encontrados percentuais de manutenção das vogais médias, em especial de /e/, ao menos um pouco maiores na fala dos informantes de diferentes níveis de escolaridade, inqueridos por questionário e leitura, quando estariam mais atentos a sua fala do que nos diálogos com o documentador.

\subsection{Resultados dos questionários e teste de leitura}

A aplicação do questionário e da etapa de leitura aos informantes cariocas totalizou 1292 dados de vocábulos proparoxítonos com vogais médias postônicas mediais, entre 738 ocorrências de vogal /e/ e 554 de vogal /o/. Infelizmente, uma das entrevistas foi desconsiderada devido à falta de espontaneidade do interlocutor, que teve um comportamento extremamente artificial a ponto de silabar grande parte das proparoxítonas proferidas em todas as etapas. Dessa forma, o total de dados, explanados na Tabela 6, a seguir, referem-se a 17 gravações:

Tabela 6 - Distribuição das 1292 ocorrências de vogal média postônica medial nos Questionários e na Leitura

\begin{tabular}{lccc}
\hline & Questionários e Leitura & \\
Estratégia & Anterior & Posterior \\
Perguntas & 279 & & 263 \\
& & Total: 542 & \\
Figuras & 202 & & 157 \\
& & Total: 359 & \\
Leitura & 257 & & 134 \\
\hline
\end{tabular}

Devidoà baixíssima produtividade nos resultados, foram desconsiderados desses números os 09 casos de cancelamento encontrados na fala popular, 08 referentes a indivíduos de nível Médio e apenas 01 de nível Fundamental. Também não são considerados na pesquisa os casos de alteração da vogal: 09 casos de abaixamento da vogal posterior /o/.

Quanto aos itens lexicais previstos, todos foram encontrados várias vezes, mas alguns tiveram muito menos produtividade nas respostas do que outros. As palavras fôlego, gênero, síntese, sonífero, tráfego, catástrofe, 
monótono e agrícola, especialmente, foram as mais difíceis de serem obtidas. Pouco lembradas pelos cariocas, quase sempre essas proparoxítonas foram preteridas diante de sinônimos extremamente comuns na fala casual, respectivamente ar, tipo (ou estilo, ritmo), resumo, calmante, movimento (ou fluxo, trânsito), tragédia (ou desastre, calamidade), repetitivo (ou chato) e rural.

Os resultados encontrados refletem, de forma geral, o que se esperava com base nos Atlas Linguísticos analisados por De Paula (2010). Mesmo assim, os dados chegaram ainda a surpreender com índices bastante elevados de conservação das vogais médias, inclusive de /o/. Os cariocas de todos os níveis de escolaridade realizaram muito mais a articulação média na concretização de ambas as vogais em comparação com os corpora sociolinguísticos, mas a vogal anterior /e/ permaneceu sendo a vogal menos propícia ao alteamento com relação a /o/, à semelhança das outras etapas da pesquisa. Os percentuais gerais para /e/ podem ser observados na Tabela 7.

Tabela 7 - Índices da realização da vogal média anterior postônica medial em dados de Questionários e Leituras

\begin{tabular}{|c|c|c|}
\hline \multicolumn{3}{|c|}{ Questionários e Leitura - Vogal /e/ } \\
\hline Estratégia & Alteamento & Manutenção \\
\hline \multirow{2}{*}{ Perguntas } & $141 / 279$ & $138 / 279$ \\
\hline & $50,5 \%$ & $49,5 \%$ \\
\hline Exemplos & ['a]piru] & ['a $\int$ peru] \\
\hline \multirow{2}{*}{ Figuras } & $92 / 202$ & $110 / 202$ \\
\hline & $45,5 \%$ & $54,5 \%$ \\
\hline Exemplos & [tef'mõmitru] & [tef'mõmetru] \\
\hline \multirow{2}{*}{ Leitura } & $98 / 257$ & $159 / 257$ \\
\hline & $38,1 \%$ & $61,9 \%$ \\
\hline Exemplos & ['kahsiri] & ['kahseri] \\
\hline \multirow{2}{*}{ Total } & 331 & 407 \\
\hline & $44,9 \%$ & $55,1 \%$ \\
\hline
\end{tabular}

Os resultados estão sempre apresentados separadamente por tipo de estratégia de investigação, visto que o estilo de fala é diferente em cada um. Os percentuais demonstram isso, já que o conjunto de falantes diminui gradualmente o processo de alteamento em /e/, conforme aumenta a formalidade do inquérito: $50,5 \%>45,5 \%>38,1 \%$. Naturalmente, a diferença na etapa de leitura é muito maior, ultrapassa a neutralidade da faixa dos $50 \%$, alcançando mais de $60 \%$ de manutenção da média /e/. No total geral, a articulação média da vogal anterior /e/ sobrepõe levemente o alteamento, em $55,1 \%$ dos casos.

Já entre os vocábulos com vogal /o/, o processo de alteamento também é refreado no discurso monitorado, mas ainda é muito mais produtivo em comparação com a vogal anterior: no total geral, foi realizado em 64,8\% dos casos. Ao observar as três estratégias de investigação, entretanto, vê-se muitas diferenças no comportamento dos cariocas.

Tabela 8 - Índices da realização da vogal média posterior postônica medial em dados de Questionários e Leituras

\begin{tabular}{|c|c|c|}
\hline \multicolumn{3}{|c|}{ Questionários e Leitura - Vogal /o/ } \\
\hline Estratégia & Alteamento & Manutenção \\
\hline \multirow{2}{*}{ Perguntas } & $185 / 263$ & $78 / 263$ \\
\hline & $70,3 \%$ & $29,7 \%$ \\
\hline Exemplos & [aw'tõ numu] & [aw'tõ nomu] \\
\hline \multirow{2}{*}{ Figuras } & $114 / 157$ & $43 / 157$ \\
\hline & $72,6 \%$ & $27,4 \%$ \\
\hline Exemplos & ['ma:fimu] & ['mafimori] \\
\hline \multirow{2}{*}{ Leitura } & $60 / 134$ & $74 / 134$ \\
\hline & $44,8 \%$ & $55,2 \%$ \\
\hline Exemplos & ['Ĩduli] & ['T̃doli] \\
\hline \multirow{2}{*}{ Total } & 359 & 195 \\
\hline & $64,8 \%$ & $35,2 \%$ \\
\hline
\end{tabular}


Apenas nas leituras a mudança da vogal posterior /o/ para $[\mathrm{u}]$ é preterida pelos falantes, que altearam a vogal em $44,8 \%$, um percentual equilibrado com a realização da vogal /e/ nos dados de leitura: $38,1 \%$ de alteamento. Nas figuras e perguntas, entretanto, a formalidade não restringe tanto a tendência de redução de /o/ e o alteamento ainda é a realização mais frequente dessa vogal. A categoricidade do processo, entretanto, não se verifica mais como se verificou em todas as entrevistas da década de 2000 e a formalidade faz os falantes reaverem a variante conservadora, de articulação média, em quase $30 \%$ dos casos, 29,7\% nas perguntas e 27,4\% nas figuras.

Embora esses dados não possam ser tratados estatisticamente, as variáveis que se mostraram mais pertinentes à variação das vogais /e/ e /o/ postônicas não finais, nas análises já empreendidas, foram, nesta etapa, controladas em percentuais, também com o auxílio do Programa Goldvarb-X. São elas a classificação lexical das proparoxítonas, no nível linguístico, a faixa etária, o sexo e a escolaridade, no nível extralinguístico.

Os falantes cariocas apresentaram diferença na realização das vogais apenas com relação à escolaridade e, embora todos mudem de comportamento em contexto formal, eles não parecem atentar para o caráter mais usual ou mais técnico das proparoxítonas, tendo comportamento semelhante ao realizar os dois tipos. Observa-se na etapa de leitura, que todos os falantes são receosos ao se deparar com esse tipo de acento, mesmo em palavras comuns na fala carioca, como véspera e prótese.

Apresenta-se, a seguir, uma observação do comportamento dos falantes com diferentes níveis de escolaridade na realização de /e/ e /o/, em cada etapa do questionário e da leitura. Nas seções a seguir, será possível perceber que o aumento dos anos de escolaridade dos falantes influenciou muito mais a realização de /e/ que a realização de /o/.

\subsubsection{Perguntas}

A etapa de 32 perguntas (e 16 distratores) foi a menos formal das três, em que os informantes não ficaram restritos apenas a respostas objetivas, mas também dialogaram com o documentador.

Em todos os níveis de escolaridade, os resultados para a vogal anterior /e/ aproximaram-se dos da fala culta nas entrevistas de tipo DID da mesma década. $\mathrm{O}$ alteamento concorre equilibradamente com a manutenção da vogal nas respostas dos cariocas, mas é preterido entre os falantes cultos:

Tabela 9 - Índices da realização da vogal média anterior postônica medial por nível de escolaridade em respostas a perguntas do Questionário

\begin{tabular}{llcc}
\hline \multirow{2}{*}{ Variável } & \multicolumn{3}{c}{ Perguntas - Vogal /e/ } \\
& Fatores & Alteamento & Manutenção \\
& \multirow{2}{*}{ Fundamental } & $41 / 75$ & $34 / 75$ \\
Escolaridade & & $54,7 \%$ & $45,3 \%$ \\
& \multirow{2}{*}{ Médio } & $56 / 105$ & $49 / 105$ \\
& & $53,3 \%$ & $46,7 \%$ \\
& \multirow{2}{*}{ Superior } & $44 / 99$ & $55 / 99$ \\
& & $44,4 \%$ & $55,6 \%$ \\
\hline
\end{tabular}

Há distinção clara entre fala culta e fala popular na realização de /e/, sendo os cultos os informantes menos passíveis a altear a vogal, enquanto os falantes com Ensino Médio não divergem muito daqueles com apenas o Fundamental.

Não está nesses percentuais um caso de cancelamento realizado por um informante com Ensino Médio: frutífera [fru'tife].

Quanto à vogal posterior, a situação das perguntas não parece influenciar muito os falantes com menos escolaridade, que mantiveram a vogal /o/ em 
apenas $17,1 \%$ das respostas. Os falantes com mais escolaridade foram mais conservadores, mas não se observa diferença entre os de Ensino Médio e Superior:

Tabela 10 - Índices da realização da vogal média posterior postônica medial por nível de escolaridade em respostas a perguntas do Questionário

\begin{tabular}{llcc}
\hline & \multicolumn{3}{c}{ Perguntas - Vogal /o/ } \\
Variável & Fatores & Alteamento & Manutenção \\
& \multirow{2}{*}{ Fundamental } & $68 / 82$ & $14 / 82$ \\
Escolaridade & & $82,9 \%$ & $17,1 \%$ \\
& \multirow{2}{*}{ Médio } & $60 / 98$ & $38 / 98$ \\
& & $61,2 \%$ & $38,8 \%$ \\
& \multirow{2}{*}{ Superior } & $57 / 83$ & $26 / 83$ \\
& & $68.7 \%$ & $31.3 \%$ \\
\hline
\end{tabular}

Nesta etapa, e de forma geral nos questionários, vê-se o resgate da variante conservadora da vogal /o/ postônica medial, à semelhança da vogal anterior. Entretanto, como se mostra nas seções a seguir, o processo de alteamento da vogal posterior só é preterido na etapa mais formal, a leitura.

Não foram calculados os 03 casos de cancelamento produzidos por informantes com Ensino Médio: 01 de pólvora ['powvja] (processo de sândi em "a pólvora e a espoleta”), 01 de [a'bsbre] e 01 de carnívoro [kafinivru].

\subsubsection{Figuras}

Na etapa de identificação de figuras, a interação com os informantes foi muito mais rápida e objetiva que na anterior. Eles forneceram quase sempre respostas objetivas, mais cuidadas e conscientes que as anteriores.
A consequência dessa postura observa-se na concretização da vogal /e/. Nessa etapa, apenas os falantes do segundo nível de escolaridade altearam preferencialmente a vogal, ainda um pouco mais que na primeira parte da gravação.

Tabela 11 - Índices da realização da vogal média anterior postônica medial por nível de escolaridade em identificação de figuras do Questionário

\begin{tabular}{llcc}
\hline & \multicolumn{3}{c}{ Figuras - Vogal /e/ } \\
Variável & Fatores & Alteamento & Manutenção \\
& \multirow{2}{*}{ Fundamental } & $27 / 54$ & $27 / 54$ \\
& & $50 \%$ & $50 \%$ \\
Escolaridade & \multirow{2}{*}{ Médio } & $44 / 77$ & $33 / 77$ \\
& & $57,1 \%$ & $42,9 \%$ \\
& \multirow{2}{*}{ Superior } & $21 / 71$ & $50 / 71$ \\
& & $29,6 \%$ & $70,4 \%$ \\
\hline
\end{tabular}

O nível Fundamental foi equilibrado ao aplicar o alteamento, alternando entre [e] e [i] com $50 \%$ de ocorrências de cada variante. Os falantes cultos mantiveram a vogal /e/ em mais de 70\% dos casos, 50 em um total de 71 .

No âmbito da vogal /o/, o aumento da formalidade não restringiu tanto o alteamento quanto se observou para a vogal /e/. Apenas os falantes com Ensino Fundamental diminuíram o percentual de alteamento com relação à fase de perguntas, os mais escolarizados realizaram percentuais próximos aos da primeira etapa e ainda foram um pouco menos conservadores:

Os falantes com nível Fundamental haviam aplicado o alteamento em $83,9 \%$ dos casos e agora aplicaram em apenas $66 \%$. Os demais não corresponderam a essa tendência: os de Ensino Médio variaram de 61,2\% de alteamento para $77,6 \%$ e os com nível Superior, de $68,7 \%$ a $73,1 \%$. 
Tabela 12 - Índices da realização da vogal média posterior postônica medial por nível de escolaridade em identificação de figuras do Questionário

\begin{tabular}{llcc}
\hline & \multicolumn{2}{c}{ Figuras - Vogal /o/ } & \\
Variável & Fatores & Alteamento & Manutenção \\
& & 31 & 16 \\
Escolaridade & Fundamental & $66 \%$ & $34 \%$ \\
& \multirow{2}{*}{ Médio } & 45 & 13 \\
& & $77,6 \%$ & $22,4 \%$ \\
& Superior & 38 & 14 \\
& & $73,1 \%$ & $26,9 \%$ \\
\hline
\end{tabular}

Foram desconsideradas, nessa contagem, as 04 ocorrências de apagamento levantadas nesta etapa: 02 casos de cócegas ['ko $\left.\mathrm{ke} \int\right], 01 \mathrm{de}$ horóscopo [Ј'rつf] e 01 de semáforo [sẽ'mafru] (um dos casos de cócegas ocorreu no nível de Ensino Fundamental e os demais no nível Médio).

Também não foram incluídos, no conjunto de dados, 09 casos de comutação de /o/ por [e], todos produzidos nessa segunda etapa do questionário. Eles referem-se a 01 caso de fósforo ['fつfferu], 01 de [se'maferu], 02 de autódromo [aw'todremu] e 05 de sambódromo [sø̃bodremu]. De 09 ocorrências, 05 concentram-se entre falantes com Ensino Médio, mas o processo não parece ser condicionado por escolaridade ou monitoramento do discurso, havendo também 02 casos entre os falantes com menos anos de escolaridade e 02 casos entre os cultos. Por outro lado, destaca-se a regularidade das sequências fonéticas em que ele ocorreu, correspondentes aos sufixos -foro e -dromo, o que indica ser um fenômeno com alguma sistematicidade, talvez de motivação morfológica.

Os resultados apresentados até agora, a respeito das etapas de perguntas e figuras, demonstraram que a vogal posterior /o/ é menos atingida pela formalidade do discurso do que a anterior /e/, quando se trata de resgatar a variante média. Mesmo assim, a situação de perguntas e respostas favoreceu a articulação média nesse contexto, a qual já havia desaparecido na fala espontânea. De forma geral, quando aumenta o monitoramento do discurso, o processo de alteamento é refreado e aumenta o percentual de manutenção das vogais, mais intensamente no âmbito de /e/, mas também de forma expressiva no âmbito de /o/.

\subsubsection{Leituras}

A etapa de leitura, obviamente, é a mais artificial das três etapas do inquérito e não corresponde de nenhuma maneira à fala espontânea, mas sim ao extremo da fala monitorada. Partindo de um texto de variedade escrita que não foi elaborado pelo informante, ela serve, entretanto, para testificar um dos níveis mais formais de elocução e fornecer as variantes escolhidas pelos falantes nesse tipo de situação discursiva.

Pôde-se observar que, ao ler os textos pedidos, quase todos os falantes com menos escolaridade leram com menos fluidez que os demais, silabaram a maioria das proparoxítonas e frequentemente se corrigiram. Os outros dois níveis de escolaridade também tiveram, várias vezes, dificuldade na identificação de proparoxítonas, pausaram diante desse tipo de acento e se corrigiram com frequência, demonstrando pouca familiaridade com alguns itens investigados. Por outro lado, alguns dos falantes com menos escolaridade, muitas vezes, não souberam em que sílaba pousar o acento das proparoxítonas, mesmo após se corrigirem e apesar do acento gráfico.

Acredita-se serem esses os motivos de os falantes do Ensino Fundamental terem realizado um percentual de manutenção da média /e/ significativamente maior do que aqueles com Ensino Médio e Superior. Desconhecendo as palavras apresentadas, o leitor menos hábil vê-se preso à forma escrita da palavra e, quase sempre, a variantes conservadoras. 
De qualquer forma, esta etapa foi a única em que os informantes de todos os níveis de escolaridade preteriram o alteamento de /e/:

Tabela 13 - Índices da realização da vogal média anterior postônica medial por nível de escolaridade em leituras

\begin{tabular}{llcc}
\hline & \multicolumn{2}{c}{ Leituras - Vogal /e/ } & \\
Variável & Fatores & Alteamento & Manutenção \\
& \multirow{2}{*}{ Fundamental } & $21 / 70$ & $49 / 70$ \\
Escolaridade & & $30 \%$ & $70 \%$ \\
& \multirow{2}{*}{ Médio } & $39 / 89$ & $50 / 89$ \\
& & $43,8 \%$ & $56,2 \%$ \\
& \multirow{2}{*}{ Superior } & $38 / 98$ & $60 / 98$ \\
& & $38,8 \%$ & $61,2 \%$ \\
\hline
\end{tabular}

Além dos índices de alteamento, explanados na Tabela 13 acima, um falante do Ensino Médio apagou a vogal /e/ em 01 ocorrência de vésperas

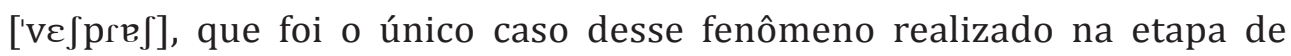
leitura.

Observou-se, nas fases de perguntas e identificação de figuras, que o comportamento de /o/ não mudou radicalmente com a escolaridade, mas foi monitorado de forma a recuperar significativamente a variante conservadora [o], que não é mais produtiva na fala espontânea. Paralelamente, constatou-se similaridade na variação entre os falantes de todos os níveis de escolaridade, com percentuais semelhantes. Nas figuras, inclusive, o Ensino Superior chegou a ser até um pouco menos conservador que o Ensino Fundamental. Tudo isso havia demonstrado que o processo de alteamento no contexto posterior não apresenta mais restrições sociais, ao contrário do que se verificou para /e/.
Nas leituras, entretanto, finalmente vê-se o monitoramento do discurso relacionar-se com a escolaridade na manutenção da vogal média posterior. Nesse estilo de fala investigado, que foi o menos natural, a articulação média foi preferida nos dois níveis mais altos de escolaridade:

Tabela 14 - Índices da realização da vogal média postônica medial /o/ por nível de escolaridade em leituras

\begin{tabular}{llcc}
\hline & \multicolumn{3}{c}{ Leituras - Vogal /o/ } \\
Variável & Fatores & Alteamento & Manutenção \\
& & $21 / 35$ & $14 / 35$ \\
& Fundamental & $60 \%$ & $40 \%$ \\
Escolaridade & & $22 / 48$ & $26 / 48$ \\
& Médio & $45,8 \%$ & $54,2 \%$ \\
& & $17 / 51$ & 34 \\
& Superior & $33,3 \%$ & $66,7 \%$ \\
\hline
\end{tabular}

Também se observa um comportamento muito simétrico entre as vogais /e/ e /o/ postônicas mediais na leitura desses falantes: os percentuais de manutenção das médias entre os informantes de nível Médio foram de 56,2\% para /e/ e de 54,2\% para /o/; entre os falantes de nível Superior, os índices foram de $61,2 \%$ para /e/ e de $66,7 \%$ para /o/.

Os falantes menos escolarizados, entretanto, continuam a demonstrar que a vogal anterior é mais sensível ao monitoramento do discurso quanto à preservação das vogais médias. Como dito, ao realizar com muita atenção proparoxítonos incomuns ou desconhecidos por eles, os falantes de nível Fundamental foram extremamente formais ao manter a vogal /e/ postônica medial em $70 \%$ dos casos. Nos vocábulos com /o/ postônico medial, entretanto, os mesmos informantes foram indiferentes à ortografia e altearam a vogal em $60 \%$ das ocorrências. 
Assim, a comparação entre a fala monitorada (questionários e leitura) e a fala espontânea (entrevistas) do Estado do Rio de Janeiro parece demonstrar que a assimetria entre a vogal anterior /e/ e a posterior /o/, é uma questão de competição entre variantes mais ou menos produtivas a depender do perfil do falante e do contexto discursivo. Mesmo se for desconsiderada a etapa de leitura, que é muito artificial, os resultados dos questionários e da leitura conjugados com as entrevistas de tipo DID apontam que, embora nunca deixem de alternar com as altas, ambas as vogais médias [e] e [o] podem ser escolhidas pelos falantes, especialmente conforme aumenta a sua consciência normativa, seja pelos anos que passou na escola, seja pela formalidade e pelo monitoramento do discurso. Igualmente, as variantes altas [i] e [u] são preferidas, quase categoricamente, quando o falante tem poucos anos de escolaridade e não está muito atento ao discurso, como na fala espontânea.

\section{Conclusão}

Os trabalhos variacionistas de De Paula e Brandão têm demonstrado que o alteamento das vogais médias /e/ e /o/ postônicas mediais é muito frequente na fala fluminense, desde a década de 1970, sendo indicativo da mudança para o quadro de três vogais /i a u/, em consonância com a hipótese de Bisol para o português do Brasil. Paralelamente, De Paula (2010) já havia apontado que o falante inquirido através de questionário pode refrear esse processo de mudança, sendo favorável à articulação média das vogais, mais conservadora, à semelhança dos falantes mais escolarizados produzindo fala espontânea.

Através do controle de questionários e leituras, observou-se, nesta etapa da pesquisa, o resgate notável das variantes médias [e] e [o] em todos os segmentos da comunidade de fala carioca. Confirmando o que havia sido previsto, o discurso monitorado provocou a realização das vogais médias na fala popular, em que elas já haviam desaparecido na fala espontânea. A comparação entre as etapas de perguntas e respostas, identificação de figuras e leitura de texto mostrou que, conforme aumenta o monitoramento do discurso, mais o processo de alteamento é refreado, principalmente na realização de /e/, mas também de forma expressiva na realização de /o/. Nesse sentido, a etapa de leitura foi a única em que os informantes de todos os níveis de escolaridade preteriram o alteamento de /e/.

A recuperação de ambas as vogais em estilos formais, como a leitura, inclusive na fala popular, demonstra que a assimetria entre elas, percebida por Câmara Jr na fala carioca da década de 1940, não é fonológica na fala fluminense. Ao contrário, considerando-se os demais resultados desta pesquisa, conclui-se que o comportamento de /e/ só se diferencia do comportamento de /o/ na fala espontânea quando há atuação da escolaridade do falante, um fator que é social e não fonológico.

Assim, observou-se mais um indício de que o comportamento diferenciado das vogais /e/ e /o/ postônicas mediais no Estado do Rio de Janeiro, embora pareça ser uma distinção de nível fonológico, na verdade é uma questão de competição entre variantes fonéticas que são mais ou menos produtivas a depender, principalmente, da influência da escolaridade e do contexto discursivo.

\section{Referências}

ALMEIDA, Fabiana da Silva Campos. Micro Atlas Fonético do Estado do Rio de Janeiro: uma contribuição para o conhecimento dos falares fluminenses. 2008. $163 \mathrm{fl}$. 2 v. Tese (Doutorado em Língua Portuguesa) - Universidade Federal do Rio de Janeiro, 2008.

ARAÚJO, Gabriel Antunes de; VIARO, Mário; GUIMARÃES FILHO, Zwinglio; OLIVEIRA, Leonardo. As proparoxítonas e o sistema acentual do português. In: ARAUJO, Gabriel Antunes de (Org.). O acento em português: abordagens fonológicas. São Paulo: Parábola, 2007. p. 37-60. 
BISOL, Leda. A simetria no sistema vocálico do português brasileiro. Linguística, v. 5, p. $41-52,2010$

A neutralização das átonas. Revista D.E.L.T.A, v. 19, n 2, p. 267-276, 2003.

CAMARA Jr., Joaquim Mattoso. Estrutura da língua portuguesa. Petrópolis: Vozes, 1970.

DE PAULA, Alessandra. Variação e mudança no vocalismo postônico medial em português. 2015. 280 fl. Tese (Doutorado em Língua Portuguesa) - Universidade Federal do Rio de Janeiro, 2015.

Vogais médias postônicas não finais no Rio de Janeiro: produtividade lexical e processo de alteamento. In: MAGALHÃES, José Sueli de (Org.). Linguística in Focus 10 Fonologia. Uberlândia: EDUFU, 2014. p. 205-228.

As vogais médias postônicas não finais em corpora de perfis sócio e geolinguísticos. Estudos Linguísticos, São Paulo, v. 38, n 1, p. 35-46, 2009.

DE PAULA, Alessandra; BRANDÃO, Silvia Figueiredo. Vogais em contexto postônico não final em variedades do português: questões teóricas. Revista da ABRALIN, São Carlos, v. 14 , n. 1 , p. $45-82$, jun. 2015.

Sobre vogais médias em posição postônica não final na fala popular do Rio de Janeiro. Letras de Hoje [online], v. 47, n 3, p. 275-282, 2012b.

Assimetria do quadro vocálico em contexto postônico não final: aspectos diacrônicos e realidades sincrônicas. Signum - Estudos de Linguagem, v. 15, n 1, p. 129-149, jun. 2012a.

LABOV, William. Sociolinguistic patterns. Philadelphia: University of Pennsylvania, 1972.

LIMA, L. G. Atlas Fonético do entorno da Baía de Guanabara - AFeBG. 2006. 2 v. $415 \mathrm{fl}$. Dissertação (Mestrado em Língua Portuguesa) - Universidade Federal do Rio de Janeiro, 2006.

MAGALHÃES, José Sueli; SILVA, André Pedro da. Ainda as proparoxítonas: apagamento e preservação da vogal postônica não final. In: DA HORA, Dermeval; NEGRÃO, Esmeralda Vailati (Org.). Estudos da linguagem: casamento entre temas e perspectivas. João Pessoa: Ideia/Ed. Universitária, 2011. p. 197-212.

RAMOS, A. P. Descrição das vogais postônicas não-finais na variedade do noroeste paulista. 2009. 175 fl. Dissertação (Mestrado em Letras) - Universidade Estadual Paulista, 2009.
RIBEIRO, D. F. S. Alçamento de vogais postônicas não finais no português de Belo Horizonte - Minas Gerais: uma abordagem difusionista. 2007. 274 fl. Dissertação (Mestrado em Língua Portuguesa e Linguística) - Pontifícia Universidade de Minas Gerais, 2007.

VIEIRA, M. J. B. Neutralização das vogais médias postônicas. 1994. 110 fl. Dissertação (Mestrado em Letras: Língua Portuguesa) - Universidade Federal do Rio Grande do Sul, 1994

As vogais médias postônicas: uma análise variacionista. In: BISOL, Leda; BRESCANCINI, Cláudia (Org.). Fonologia e variação: recortes do português brasileiro. Porto Alegre: EDIPUCRS, 2002. p. 127-159.

As vogais médias átonas nas três capitais do sul do país. In: BISOL, Leda; COLLISCHONN, Gisela (Org.). Português do sul do Brasil: variação fonológica. v. 1. Porto Alegre: EDIPUCRS, 2009. p. 50-72.

WEINREICH, Uriel; LABOV, William; HERZOG, Marvin. (1968). Fundamentos empíricos para uma teoria da mudança linguística. Tradução de Marcos Bagno. São Paulo: Parábola 2006

Recebido em 28/09/2016 Aceito em 06/02/2017. 